Lepr Rev (1994) 65, 122-129

\title{
A survey to determine the prevalence of leprosy in a community in East Trinidad
}

\author{
M. SUITE, N. B. EDINBOROUGH, M. LEWIS* \& \\ J. TOLLEFSON† \\ Hansen's Disease Control Unit (Ministry of Health), 182 Western \\ Main Road, Cocorite, Trinidad; *Public Health Laboratory \\ (Ministry of Health), Jamaica Boulevard Federation Park, \\ Trinidad; and †Caribbean Epidemiology Centre (PAHO/WHO), \\ Jamaica Boulevard, Federation Park, Trinidad
}

Accepted for publication 12 October 1993

\begin{abstract}
Summary A house-to-house survey was conducted in a community in East Trinidad, where a clustering of cases had been observed. There were 1355 residents, of whom $73.5 \%$ had a complete visual skin examination.

No new cases of leprosy were found but a variety of skin disorders were diagnosed. The most common disorder was pityriasis versicolor, which is one of the differential diagnoses of hypopigmented skin lesions. This has serious implications for the delayed diagnosis of leprosy.

In all, 5 of the 9 old cases residing in the survey area suffered from paucibacillary disease, and had a history of contact with a lepromatous case. They were not listed initially as contacts of this index case. Contact lists should theref ore include nonf amilial persons having frequent contact with an index case. The definition of 'frequent' should be determined by each programme.

It may also be necessary to review the duration of surveillance of contacts. The survey was estimated to have cost about US $\$ 2,500$ and was not considered to be cost-effective.
\end{abstract}

\section{Introduction}

Leprosy exists at low endemic levels in Trinidad and Tobago, as is demonstrated by the annual prevalence rates (measured by cases registered for treatment) which have fluctuated from 6 to 10 per 100,000 population between 1985 and 1990. It has been noted that the county of St George East in northern Trinidad has the highest leprosy incidence rate for the country, providing about $40 \%$ of new cases annually between 1985 and 1990, while accounting for about $16 \%$ of the population of Trinidad and Tobago. Clustering of cases has been observed in some communities but not all of it has been familial.

The main aim of the study was to assess the true prevalence of leprosy in a community in St George East county where clustering had been observed. We also 
wished to determine whether active case-finding by means of a house-to-house survey in such an area is an effective means of detecting new cases. In addition, the study was to provide a service of consultation for nonleprosy skin diseases.

\section{Material and methods}

The survey was conducted by 3 teams of investigators in February and March 1991, and 1 week before the survey commenced householders were notified by a public address system that a 'skin survey' was to take place. No mention was made of leprosy. An explanatory letter (Figure 1) was presented to each householder and a standardized questionnaire was given to those who accepted this. Household members who agreed had a visual examination of the entire skin, or exposed areas of face, arms and legs if this was preferred.

Sensory testing (light touch and pinprick) was conducted if thought necessary, but nerves were not examined for enlargement. People with suspicious lesions, as well as those desiring consultation, were referred to the Dermatology Clinic. Investigators were allowed to make up to 3 visits to the household in order to obtain maximal coverage.

\section{Results}

Of 286 eligible households, 2 refused to participate; 35 premises in the survey area were either unoccupied or demolished and were not included. Data were available for up to 1355 people from 284 households.

Leprosy prevalence for the survey area based on the 2 known cases still on the treatment register was $14 \cdot 8$ per 10,000 population. No new cases were found and the estimated prevalence was not altered by this survey.

\section{DEMOGRAPHIC DATA}

Gender data was recorded for 1328 people, and $47 \cdot 4 \%$ were male and $52 \cdot 6 \%$ female. Age data were available for 1329 people and 32.9\% (446/1329) were under 15 years old (Table 1), a similar distribution to that of Trinidad and Tobago as a whole, where children represent $31 \cdot 3 \%$ of the population (Central Statistical Office-1990). About

\section{Dear Householder,}

The Ministry of Health is conducting a survey of skin diseases in your area. You are kindly asked to cooperate with the interviewer as necessary. A brief examination of the entire skin will be done, free of charge. With your consent, the health worker will examine your skin and ask a few simple questions. Persons who have skin disorders requiring treatment or further tests will be given a referral to the nearest skin clinic or to the skin clinic at the General Hospital, Port of Spain (free of charge). You may refuse to be examined if you are uncomfortable about it. However, it will greatly assist us if you allow yourself and your family to be examined. All information will be kept strictly confidential. Thank you.

Figure 1. Introductory letter to householders. 
Table 1. Age distribution of population

\begin{tabular}{lc}
\hline Age (years) & No. of persons (\%) \\
\hline $0-14$ & $446(32 \cdot 9)$ \\
$15-29$ & $410(30 \cdot 3)$ \\
$30-44$ & $242(17 \cdot 9)$ \\
$45-59$ & $147(10 \cdot 8)$ \\
$60-74$ & $61(4 \cdot 5)$ \\
$75-89$ & $22(1 \cdot 7)$ \\
90 and over & $1(0 \cdot 1)$ \\
Not recorded & $26(1 \cdot 9)$ \\
& \\
Total & $1355(100 \cdot 1)$ \\
\hline
\end{tabular}

$50 \%$ were Africans (670/1335) and 30\% were East Indians (404/1335), which is not significantly different from the statistics for the whole county (African, 50.3\%; East Indian, $25 \cdot 1 \%$ ) but differs significantly from the general population, where Africans account for $40 \cdot 8 \%$ of the population and East Indians $40 \cdot 7 \% ; 19 \%$ were of mixed race.

\section{OCCUPATION OF HEAD OF THE HOUSEHOLD}

About $23 \%$ of household heads had occupations in the community social and personal services, $14 \%$ were unemployed and close to $10 \%$ were employed in each of the manufacturing, agriculture and transport and communications sectors or were retired from jobs. Fewer breadwinners were employed in other sectors such as petroleum, construction, restaurants and the utilities.

\section{LENGTH OF RESIDENCE}

The period of residence in the survey area for household members varied from a few months to 79 years. People who had lived in the household for less than 3 months were not included in order to rule out transients (Table 2). Just over 50\% were spouses and children of the head of the household.

Table 2. Length of residence in the survey area

\begin{tabular}{lc}
\hline Length of residence (years) & No. of persons $(\%)$ \\
\hline $3-9$ months & $625(46 \cdot 1)$ \\
$10-29$ & $365(26 \cdot 9)$ \\
$30-39$ & $227(16 \cdot 8)$ \\
$40-49$ & $82(6 \cdot 1)$ \\
$50-59$ & $22(1 \cdot 6)$ \\
$60-79$ & $11(0 \cdot 8)$ \\
Not recorded & $23(1 \cdot 7)$ \\
Total & $1355(100 \cdot 0)$ \\
\hline
\end{tabular}




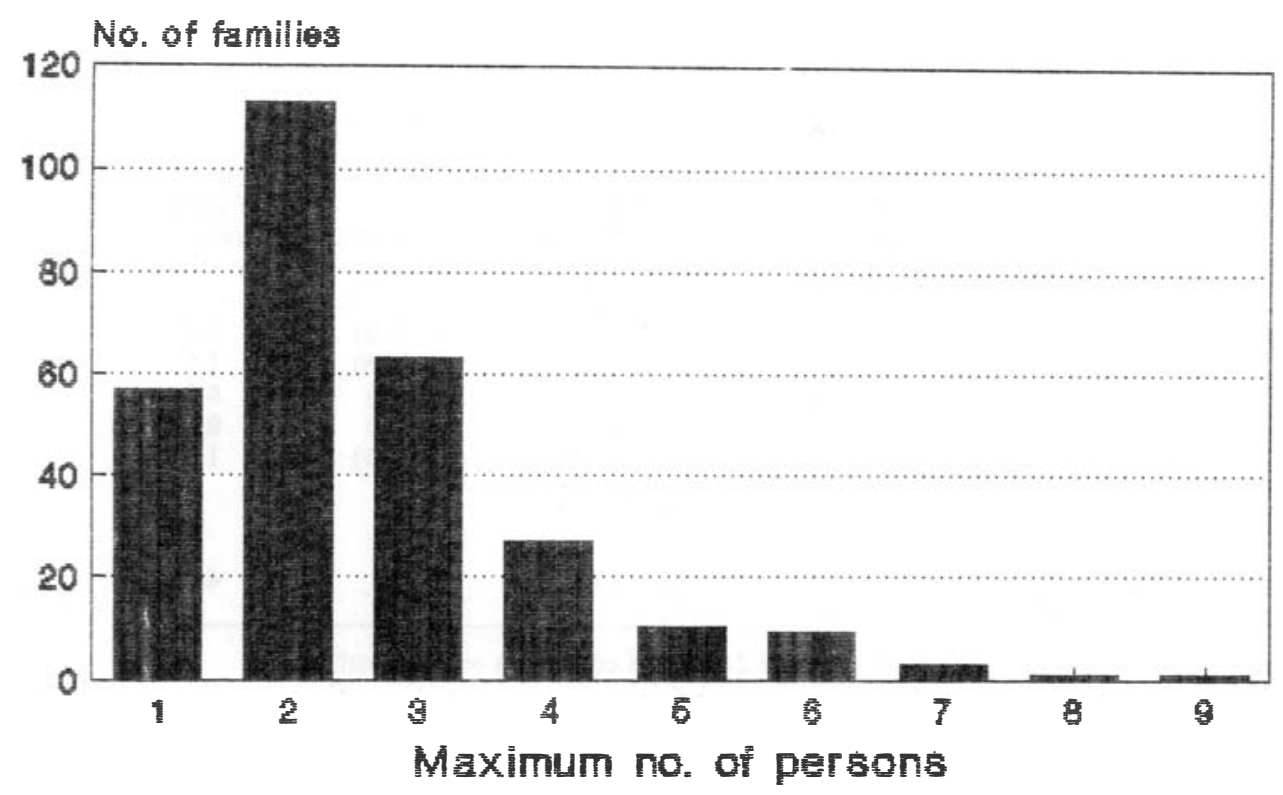

Figure 2. Occupancy of sleeping rooms.

\section{SANITARY FACILITIES}

About $77 \%$ of the households had a regular pipeborne water supply. No household received a truck-borne supply nor did any collect water from springs or rivers. Toilet facilities were adequate, with 211 households $(74 \cdot 3 \%)$ having WC systems unlinked to a sewer; $73(25 \cdot 7 \%)$ had pit latrines.

\section{SLEEPING FACILITIES}

Sleeping rooms were considered crowded if 4 or more people slept in them, regardless of size. By this standard, 16.9\% of households had overcrowded sleeping rooms (Figure 2), which corresponds to the national average of $17 \%$ of households with 4 or more persons per sleeping room.

\section{RESULTS OF SKIN EXAMINATION}

We did not examine 120 of the 1355 subjects (8.9\%); either they were not at home when the household was surveyed, or an examination was refused.

\section{FULL SKIN EXAMINATION}

A total of 995 people ( $73.5 \%$ of the eligible population) had a complete skin examination and were found to be normal; 90 people had disorders which were not conclusively diagnosed by the field workers; 1 was considered to suffer from leprosy, but subsequently in the clinic she was diagnosed as suffering from an achronic naevus. She was the granddaughter of a deceased case who had been discharged. 
Table 3. Distribution of diagnoses made in the field and in the dermatology clinic

\begin{tabular}{|c|c|c|c|c|}
\hline \multirow[b]{2}{*}{ Skin disorder } & \multicolumn{2}{|c|}{ Field diagnosis } & \multicolumn{2}{|c|}{ Clinic diagnosis } \\
\hline & $\begin{array}{c}\text { No. of } \\
\text { persons }(\%) \\
(n=183)\end{array}$ & $\begin{array}{c}\text { Percent } \\
\text { of sample } \\
\text { examined } \\
(n=1235)\end{array}$ & $\begin{array}{c}\text { No. of } \\
\text { persons }(\%) \\
(n=52)\end{array}$ & $\begin{array}{c}\text { Percent } \\
\text { of sample } \\
\text { examined } \\
(n=1235)\end{array}$ \\
\hline Pityriasis versicolor & $66(36 \cdot 1)$ & $5 \cdot 3$ & $16(30 \cdot 8)$ & $1 \cdot 3$ \\
\hline Eczema & $9(4 \cdot 9)$ & $0 \cdot 7$ & $19(36 \cdot 5)$ & $1 \cdot 5$ \\
\hline Scabies & $8(4 \cdot 3)$ & 0.6 & $4(7 \cdot 7)$ & $0 \cdot 3$ \\
\hline Acne & $5(2 \cdot 7)$ & 0.4 & $4(7 \cdot 7)$ & $0 \cdot 3$ \\
\hline Naevi and others & $4(2 \cdot 2)$ & $0 \cdot 3$ & $12(23 \cdot 1)$ & $1 \cdot 0$ \\
\hline Psoriasis & $1(0 \cdot 5)$ & $0 \cdot 1$ & & \\
\hline Unknown & $90(49 \cdot 2)$ & $7 \cdot 3$ & & \\
\hline Total & $183(99 \cdot 9)$ & $14 \cdot 7$ & $55^{*}$ & $4 \cdot 4$ \\
\hline
\end{tabular}

* There were 3 subjects who had 2 different conditions on examination.

EXAMINATION OF EXPOSED AREAS ONLY (FACE, ARMS, LEGS)

A total of 48 people (3.8\%) allowed a partial examination; $7 \%(93 / 1355)$ had skin problems either recognized by the field workers or they had information from previous medical consultations available. Pityriasis versicolor was the most common diagnosis (Table 3) and 1 subject had an undiagnosed skin disorder but it was not thought to be leprosy.

\section{REFERRALS}

A total of 99 people ( $7 \cdot 3 \%$ of the population) were referred to the Dermatology Clinic but only 52 presented for assessment by the medical officer. The final diagnoses are shown in Table 3.

\section{OLD CASES}

There were 9 known leprosy cases and the relevant details are shown in Table 4 .

The longest diagnosed (Case 9) had moved to the area from the leprosarium 39 years before. She was bacteriologically negative in 1971 and on subsequent examination.

Cases 2 and 3 (mother and daughter) had definite contact with a lepromatous case (GC, diagnosed in 1984 and now deceased), who had shared their premises for about 18 years, but they were not listed as his contacts. These 2 women had also cared for him in his later years while he was bacteriologically negative. Case 5 was diagnosed 2 months before Case 6 and 9 months before Case 7, both of whom were her nephews. They all had tuberculoid disease and were discovered to have been frequent visitors of GC (referred to above) who lived next door, but they also were not listed as his contacts. Of the 8 cases that were diagnosed between 1981 and 1990 who were still living in the survey area, 5 had a definite history of contact with GC, an active case of leprosy. 
Table 4. Characteristics of 'old' cases

\begin{tabular}{|c|c|c|c|c|c|c|c|c|c|}
\hline $\begin{array}{l}\text { Case } \\
\text { no. }\end{array}$ & $\begin{array}{l}\text { Age at } \\
\text { time of } \\
\text { survey } \\
\text { (years) }\end{array}$ & Sex & $\begin{array}{l}\text { Ethnic } \\
\text { origin }\end{array}$ & $\begin{array}{c}\text { Year of } \\
\text { diagnosis }\end{array}$ & Type & $\begin{array}{l}\text { Resident } \\
\text { survey } \\
\text { area at } \\
\text { time of } \\
\text { diagnosis }\end{array}$ & $\begin{array}{l}\text { History of } \\
\text { contact }\end{array}$ & $\begin{array}{c}\text { Period of } \\
\text { residence } \\
\text { in survey } \\
\text { area } \\
\text { (years) }\end{array}$ & Status at time of survey \\
\hline 1 & 36 & $\mathrm{~F}$ & EI & 1987 & BT & No & Yes (inactive) & $1 \frac{1}{2}$ & Had MDT \\
\hline $2^{*}$ & 58 & $\mathbf{F}$ & AF & 1990 & TT & Yes & Yes & $25^{2}$ & On MDT \\
\hline $3^{*}$ & 41 & $F$ & AF & 1990 & BT & Yes & Yes & 25 & On MDT \\
\hline 4 & 29 & $\mathrm{~F}$ & EI & 1985 & TT & No & No & 5 & Had MDT discharged \\
\hline $5^{*}$ & 29 & $\mathrm{~F}$ & AF & 1984 & TT & Yes & Yes & 29 & Had MDT discharged \\
\hline $6^{*}$ & 12 & $\mathbf{M}$ & AF & 1985 & TT & Yes & Yes & 12 & Had MDT discharged \\
\hline $7^{*}$ & 14 & $\mathbf{M}$ & $\mathrm{AF}$ & 1984 & TT & Yes & Yes & 14 & Had MDT discharged \\
\hline 8 & 15 & $\mathrm{~F}$ & AF & 1983 & TT & Yes & No & 12 & Had MDT discharged \\
\hline 9 & 79 & $\mathrm{~F}$ & EI & 1930 & TT & No & No & 39 & No MDT \\
\hline
\end{tabular}

* Same index case-Lepromatous.

AF, African; EI, East Indian; MDT, multidrug therapy.

\section{Discussion}

In this control programme, we relied almost entirely on notification, voluntary reporting and contact examination to discover new cases. Our largest surveys were of the populations of the schools attended by the index cases, and this method has not been productive in the past.

The survey was undertaken as a pilot study to assess the prevalence of leprosy in a community where a clustering of cases had been noted. The prevalence remained the same because no new cases were found as a result of the survey. Another aim of the study was to determine whether this survey format could be followed by others in similarly affected areas. It has been suggested that active case-finding by means of surveys is time consuming and expensive and is not likely to be productive in areas of low endemicity. ${ }^{1}$ The survey lasted for 35 working days (each day about 8 hours and each team averaging 12 days) and the estimated cost was about US $\$ 2,500$. No new cases were found and we do not believe that the exercise was cost-effective.

The reception given to the investigators was good and it is encouraging that as many as $91.1 \%$ of participating individuals had their skin examined either totally or partially. Co-operation may have been improved by not mentioning leprosy. Since 120 subjects were not examined and 48 did not allow a complete examination, our data can be considered incomplete. A review of surveys conducted in Bombay, India ${ }^{2}$ determined that $60 \%$ of lesions were found on the covered areas of the body, suggesting that examination of the entire skin is of considerable importance, but compliance is more likely to be favourable if exposed parts only are examined.

Our field workers had considerable experience in contact examination and only 1 had less than 6 months' experience in leprosy control activities. No examination of nerves was required because the incidence of purely neural disease is believed to be low in our population (3.1\% of all new cases from 1986 to 1990). In addition, the assessment of nerve enlargement is subject to much interobserver variation. W. Bhakti ${ }^{2}$ has commented that although nerve enlargement was often present in lepromatous cases, emphasis 
was infrequently placed on its importance in case detection. This is worthy of further consideration since, in Trinidad and Tobago, we tend to emphasize the presence of a hypopigmented spot as an early presenting sign and then proceed to demonstrate any sensory deficit. Other signs, e.g. cutaneous infiltration, if subtle, may not be perceived by field workers as being abnormal, but when these cases are examined later they may be found to have nerve enlargement and to be smear positive.

Pityriasis versicolor, an of ten hypopigmented skin disorder, was a common diagnosis $(30 \cdot 8 \%$ - 66/183) made in the field and was the most common clinically diagnosed condition overall. In our experience, patients frequently admitted that they believed leprosy lesions to be 'lota' (a local term for pityriasis versicolor) and had applied therapy thought to be appropriate for this disorder. They have also volunteered that this diagnosis was made by their physicians. Misdiagnosis of hypopigmented lesions bears important implications for the detection of early disease.

Although no new cases were found, we were able to examine more closely some of the characteristics of the known cases. Social and economic conditions for the area as a whole were quite satisfactory. Households where 8 of the 9 'old' cases resided had pipeborne water and a WC. Overcrowding of the sleeping accommodation occurred in households where 2 of these cases resided. The classification of occupation by employment sector did not give any indication of economic status.

Of the 'old' cases, 8 could conceivably have contracted their illness while resident in the survey area. Close contact was definite in 5 cases with nonlepromatous disease and the likely source of infection was lepromatous. This is consistent with findings elsewhere 3 which indicate that the occurrence of disease in contacts of lepromatous cases is higher than that in contacts of nonlepromatous cases. The source was nonfamilial and new infection occurred in 3 different households. It is conceivable that other factors apart from genetics and household contact are operating within this cluster. The features of the 'old' cases reinforce the need to examine the contact situation carefully, and to extend the definition of 'close' contacts to include persons having frequent contact, but not living in the same household. Such persons should be regularly examined, as well as educated about signs of disease. Admittedly, it is difficult to determine what is frequent contact and thus many contacts are inadvertently omitted from contact lists. This would have to be determined for each programme.

This programme examines contacts yearly for 5 years after diagnosis of the index case. For leprosy an incubation period of $2-5$ years is accepted but a wide range has been reported. ${ }^{4}$ Because of this factor, as well as the likelihood of missed contacts, our current period of surveillance may be inadequate.

\section{Acknowledgments}

We wish to acknowledge the contribution of the staff of the Epidemiology Department at the Caribbean Epidemiology Centre and the field and office staff of the Hansen's Disease (Leprosy) Control Unit without whom the survey would not have been possible. We also wish to thank Mrs Y. Holder, Dr R. Paul and Dr D. Quamina for their helpful comments. Dr Jan Tollefson participated in this study as a final year resident in Community Medicine, University of British Columbia. She was attached to CAREC as an epidemiologist in training. 


\section{References}

1 WHO Guide to Leprosy Control. 2nd Edition. Geneva 1988, pp. 14-16.

2 Bhakti W. Case detection: are the present survey methods effective? A review of leprosy surveys in Bombay. Lepr Rev, 1988; 59: 239-44.

3 WHO Technical Report Series 716. Epidemiology in relation to control. Geneva, 1985. p. 20.

4 Noordeen SK. The epidemiology of leprosy. In: Leprosy, Hastings RC (ed.). Edinburgh: Churchill Livingstone, p. 24, 1989. 